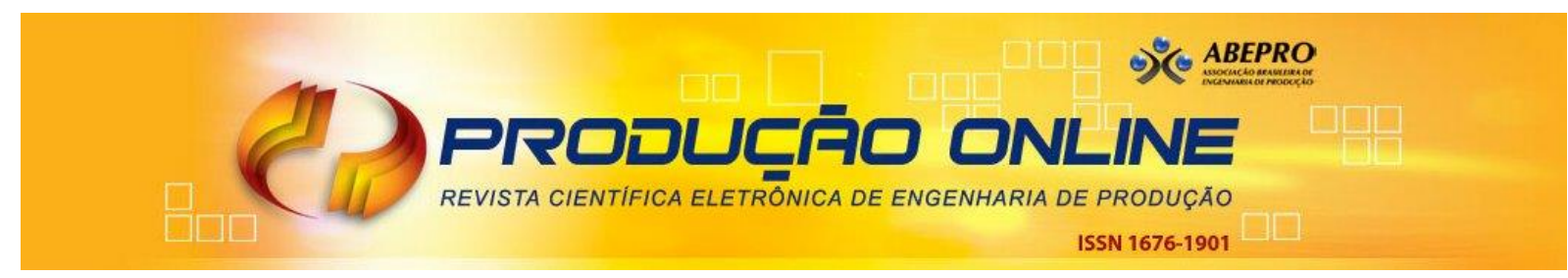

\title{
INOVAÇÃO EM INSTITUIÇÃO MILITAR DE PESQUISA: UM ESTUDO DE CASO EXPLORATÓRIO
}

\section{INNOVATION IN A MILITARY RESEARCH INSTITUTION: AN EXPLORATORY CASE STUDY}

\author{
Luiz Carlos Pereira de Almeida* E-mail: luizalmeida@cruiser.com.br \\ Emmanuel Paiva de Andrade* E-mail: emmanueluff@gmail.com \\ Rebeca Santos Alencar* E-mail: rebecaalencar@id.uff.br \\ Walber Santos de Assis* E-mail: wbassis@hotmail.com \\ Andreia Maria da Silva* E-mail: amsilva@ien.gov.br \\ *Universidade Federal Fluminense (UFF), Niterói, RJ
}

\begin{abstract}
Resumo: As instituições públicas de pesquisa são componentes essenciais do sistema nacional de inovação e, no caso de instituições militares, atuam como veículos por meio dos quais países em desenvolvimento podem adquirir conhecimento e competência sobre tecnologias industriais. $O$ presente trabalho examina a presença de fatores de gestão favoráveis à inovação em instituições militares de pesquisa. A abordagem foi qualitativa e exploratória e, além das fontes bibliográficas, teóricas e empíricas, foi feita pesquisa de campo, através de observação direta, da aplicação de questionários baseados na auditoria de processos de gestão da inovação propostos por Tidd, Bessant e Pavitt (2008) e de entrevistas abertas com a intenção de validar o desenho da pesquisa. $O$ resultado mostrou em ambas as instituições examinadas a presença dos componentes que caracterizam uma organização inovadora, com predominância das características da condição estável e, em menor dimensão, da inovação de ruptura. Foram detectadas diferenças entre as instituições, atribuíveis a características de natureza organizacional, de sistemas internos de comunicação e de regimes tecnológicos diferenciados com reflexo sobre as concepções acerca do conceito e da dinâmica da inovação.
\end{abstract}

Palavras-chave: Inovação. Inovação em condição estável. Inovação de ruptura. Instituições Militares de Pesquisa. Sistemas Nacionais de Inovação.

Abstract: Public research institutions are an important part of the national innovation system. Among these, military research institutions, can contribute to developing countries to acquire knowledge and competence in industrial technologies. This study aims to find innovation management factors in military research institutions. The approach was qualitative and exploratory, using evidence from theoretical and empirical literature as well as field research, through direct observation, questionnaires based on audit innovation management processes proposed by Tidd, Bessant and Pavitt (2008) and open interviews with the intent to validate the research design. The result shows in both institutions examined the presence of components featuring an innovative organization, especially the characteristics of incremental innovation. It found differences between the institutions, due to the organizational structure, internal communication systems and different technological schemes with reflection on the concept and dynamics of innovation.

Keywords: Innovation. Incremental Innovation. Radical Innovation. Military Research Institution. National Innovation System. 


\section{INTRODUÇÃO}

A relevância e atualidade da inovação decorrem de sua comprovada influência como propulsora do desenvolvimento de países e empresas, atravessando amplos segmentos da economia e se estendendo do setor público ao privado indistintamente. A importância cresce quando se trata de país como o Brasil, com características geopolíticas e econômicas de destaque, e mais particularmente ainda, quando se refere a um componente das Forças Armadas, como a Marinha do Brasil, dispositivo estratégico nos marcos da defesa nacional. A urgência e relevância assumem dimensões estratégicas quando se constata 0 intenso movimento de introdução de inovações tecnológicas na área de defesa pelas nações do primeiro mundo, colocando na ordem do dia o risco de defasagem tecnológica (DE NEGRI, 2008; DOLOREUX, MELANÇON, 2008).

O Manual de Oslo (OCDE, 2004), já desde sua primeira versão, apontava para dois tipos de competências envolvidas na dinâmica da inovação. De um lado, as competências estratégicas, incluindo a visão de longo prazo, a capacidade de identificar fatos portadores de futuro, como perceber e antecipar tendências de mercado, ter capacidade de reunir, organizar e processar informações tecnológicas e econômicas.

Por outro lado, o Manual falava em competências organizacionais, capazes de dar à organização disposição para o risco e a capacidade de gerenciá-lo, capaz de produzir cooperação interna entre setores da organização e cooperação externa com consultorias, clientes, fornecedores, o envolvimento de toda a organização no processo de mudança, além, naturalmente, da centralidade que começava a emprestar ao fator humano.

Nessa linha, o Manual chama a atenção para o fato de que a conscientização da importância da inovação fez com que esta fosse incluída na agenda política da maioria dos países desenvolvidos, lembrando que as políticas de inovação são a consequência estratégica de políticas de ciência e tecnologia, em diálogo produtivo com as políticas industriais.

Se no inicio se considerava que o progresso tecnológico decorria de um processo linear, originado a partir da aplicação da pesquisa básica científica, com o foco dos governos direcionado à política científica, logo se percebeu que o processo era integrado, surgindo a concepção dos chamados Sistemas Nacionais de Inovação, produzindo uma visão da inovação sistêmica, com ênfase na importância da difusão de conhecimentos, de habilidades e de informações (OCDE, 2004).

Desde os anos 1990, há uma farta produção brasileira de pesquisa e publicações sobre economia e gestão da inovação com enfoques variados, todos tentando compreender, ao seu modo e a partir de suas ênfases, os nexos entre a dinâmica da inovação e o desempenho final do sistema e/ou da organização em cujo interior se procura diagnosticar, medir ou avaliar a inovação. Silva e Hasenclever (2014) analisam nexos de causalidade entre características específicas do regime 
tecnológico e a emergência de padrões industriais de estratégia inovativa das firmas. Figueiredo e Fonseca (2014) examinam o processo de acumulação de capacidades tecnológicas e suas implicações para o aprimoramento de performance operacional. Gadelha et al (2013) analisam diferentes fatores que condicionam a dinâmica de produção e de inovação no conjunto de atividades que integram a produção de bens e serviços de saúde no Brasil. Lazzari et al (2014), utilizando análises quantitativas, vão constatar que os esforços de inovação de empresas brasileiras de capital aberto estão alinhados com performance superior das mesmas, mesmo tomando por base indicadores financeiros, que não são os mais apropriados para capturar políticas e práticas de inovação. A variedade de enfoques é compatível com a complexidade e a permeabilidade que a temática da inovação vem assumindo na sociedade brasileira.

É dentro deste contexto diversificado, complexo e em construção, que o presente artigo traz a temática da inovação em instituição militar, particularmente explorando a dicotomia clássica entre inovação em condição estável e inovação de ruptura. Se as organizações, nas palavras de Govindarajan e Trimble (2010), não são construídas propriamente para a inovação, mas sim para a execução, é razoável supor que, no caso militar, essa afirmação possa assumir proporção maior ainda, em face da cultura militar, basicamente fundada na disciplina e na hierarquia, componentes importantes do modo execução. Sendo assim, o artigo quer contribuir para a discussão da temática, a partir da realização de uma auditoria de gestão da inovação em duas Instituições Científicas e Tecnológicas (ICTs) da Marinha do Brasil.

A relevância do estudo é proporcional à importância estratégica que vem assumindo o trabalho de pesquisa das ICTs da Marinha na área de defesa, em um momento particularmente delicado, com a descoberta e exploração do pré-sal e os seus desdobramentos sobre a estratégia de defesa do país. As instituições militares de pesquisa, como organizações governamentais, exercem, na análise de Bin (2008), papel essencial "no âmbito dos sistemas de inovação, na medida em que atuam como veículos por meio dos quais os países em desenvolvimento são capazes de ganhar conhecimento e competência sobre tecnologias industriais dos países desenvolvidos" (BIN, 2008, p. 135).

\section{REVISÃO DA LITERATURA}

Para Tigre (2006), a inovação tecnológica constitui um dispositivo essencial para impulsionar desenvolvimento econômico de regiões e países. A percepção do papel estratégico da inovação tem suas origens nos estudos precursores realizados no início do século passado por Joseph Schumpeter. Schumpeter(1942) vê a inovação como um processo de "destruição criativa", onde ocorre uma busca constante pela criação de algo novo que destrói regras antigas e estabelece novas, sempre com o objetivo de obter novas fontes de lucratividade. 
No decorrer do tempo, com a necessidade crescente de se estabelecer padrões mínimos para medições no campo da inovação, foi constituído, pela Organização para Cooperação e Desenvolvimento Econômico, o Manual de Oslo, com traduções publicadas pela FINEP. Segundo o Manual, a inovação desempenha um papel central em uma economia baseada no conhecimento, reconhecendo que há um significativo conjunto de evidências no nível macro de que a inovação é, de fato, fator dominante no crescimento econômico nacional e nos padrões do comércio internacional. No nível micro (dentro das empresas), a pesquisa e desenvolvimento (P\&D) é considerada como o principal fator responsável pela capacidade de absorção e utilização pelas empresas de novos conhecimentos, não só tecnológicos, mas de todos os tipos (OCDE, 2004 e 2007).

A segunda edição do Manual de Oslo enfocava, basicamente, a inovação tecnológica, ou seja, aquela que envolve o emprego de tecnologia. Nesta perspectiva, Inovações Tecnológicas em Produtos e Processos (TPP) compreendem as implantações de produtos e processos tecnologicamente novos e substanciais melhorias tecnológicas em produtos e processos. Grizendi (2011) lembra que foi apenas a terceira edição do Manual de Oslo (OCDE, 2007) que expandiu o conceito de inovação, acrescentando dois novos tipos - inovação organizacional e de marketing.

No que se refere ao grau de novidade, as inovações podem variar desde melhorias incrementais menores até mudanças realmente radicais, que podem abranger de componentes até subsistemas ou um sistema completo. Segundo Robertson et al (2012), inovações incrementais não ocorrem de forma agregada, mas são resultado de decisões dentro de negócios individuais que podem, tanto melhorar a vantagem competitiva das empresas, como ajustá-las a mudanças em seus ambientes.

Schumpeter (1942), se refere a dois padrões arquetípicos básicos de comportamento que levam à inovação. De um lado, o processo por ele denominado de "destruição criativa", no qual as inovações são introduzidas esporadicamente pelas empresas, alterando profundamente seus produtos e processos e causando grandes alterações na economia, razão pela qual denominou o padrão de "destruição criativa". Por outro lado, há o padrão denominado "acumulação criativa", no qual as inovações constituem uma prática sistemática e estruturada da empresa introduzir novos produtos e processos.

Para Figueiredo (2009), a inovação de ruptura, por ele denominada inovação radical, se caracteriza como a construção de um novo conceito para o mercado, em que novos componentes e elementos são combinados de uma maneira diferente formando uma arquitetura nova. Sundarraj (2016), estudando o impacto sobre a performance organizacional dos dois padrões schumpeterianos básicos, conclui que, ao menos entre as empresas de tecnologia, as que são marcadas pelo padrão da acumulação criativa, e portanto pela inovação incremental, obtêm melhores resultados em termos de performance e de capacidade de superação dos problemas 
organizacionais em geral do que aquelas movidas pelo padrão da destruição criativa.

Tidd, Bessant e Pavitt (2008) ressaltam a importância da inovação incremental, por ser aquela mais presente e frequente na vida das organizações, afetando e sendo afetada pelo seu cotidiano e com um potencial, sempre presente, de transformar este mesmo cotidiano, inscrevendo-se por isso em uma perspectiva de gestão inevitavelmente estratégica. Segundo eles, há indicações de que as inovações realmente novas representam apenas cerca de 6 a $10 \%$ de todos os projetos ditos inovadores. Citam, ainda, estudos indicando que os ganhos cumulativos de eficiência resultantes da inovação incremental são maiores no longo prazo do que aqueles obtidos com as mudanças radicais ocasionais.

A este propósito, Brem et al. (2016) afirmam que a performance inovativa de uma indústria é influenciada pelo surgimento e consolidação de um design dominante, afetando inclusive o tipo de inovação que irá predominar na indústria. Eles confirmaram com uma vasta base de dados, incluindo o exame de 2,6 milhões de patentes do período de 1978 até 2013, o modelo de Abernathy-Utterback (1978), segundo o qual as inovações em produtos ocorrem nos estágios iniciais da indústria, ao passo que a emergência de um design dominante desloca o tipo de inovação do produto para o processo.

Entre as perspectivas da inovação incremental e da inovação de ruptura, com suas exigências específicas de competências e habilidades, surge a necessidade, em algumas circunstâncias, de se implementar estratégias que dêem conta das duas categorias de arquétipos de inovação. É o que os estudiosos chamaram de ambidestralidade, definida como a capacidade da organização de gerenciar atividades conflituosas e tensionamentos variados no interior da organização. Agostini et al. (2016) propõem um modelo de integração que leve em consideração o fato de que é possível estruturar-se em um nível mais elevado as soluções que são desenvolvidas nos níveis mais básicos da estrutura e do contexto organizacional (NOSELLA et al., 2012, TUSHMAN, O'REILLY, 1996).

Para Grizendi (2011), gestão da inovação, ou gestão estratégica da inovação, é o processo estruturado, contínuo e facilitador pelo qual uma empresa ou organização gera mais inovação e cria mais valor com essas inovações. Bessant e Tidd (2009), chamando a atenção para as diferenças entre o gerenciamento da execução e o gerenciamento da inovação, acrescentam a necessidade de compreender bem o que se está tentando gerir para que se possa desenvolver formas específicas de se gerenciar. Tudo isso sem perder a perspectiva estratégica da organização e, portanto, conhecendo o porquê e o quando da atividade de inovação. O uso de instrumental inadequado para avaliar e financiar os projetos de inovação, que se fixem no curto prazo, podem comprometer a capacidade inovativa da organização e deteriorar sua performance (CHRISTENSEN, KAUFMAN, SHIH, 2008). 
O ambiente também desempenha papel relevante neste sentido com a maior ou menor propensão à formação de redes de inovação. Schott e Jensen (2016) chamam a atenção para a importância das políticas nacionais que dão suporte à formação de redes e que redundam, no final das contas, em inovação. Os autores afirmam que tais políticas institucionais podem não ter impacto significativo sobre a quantidade de redes formadas mas, com certeza, impactam a qualidade das redes e portanto a sua capacidade de transformar conhecimento em inovação, tanto de produto quanto de processo.

O modelo de gestão integrada da inovação proposto por Tidd, Bessant e Pavitt (2008), apresentado na Figura 1, reúne, em conjunto com as fases do processo de inovação, quatro grupos de comportamentos que representam rotinas importantes a serem praticadas pelas organizações para o sucesso das atividades inovadoras: estratégia, contexto organizacional apoiador, relacionamentos externos eficazes e mecanismos de implementação eficazes.

Figura 1 - Modelo de gestão integrada da inovação

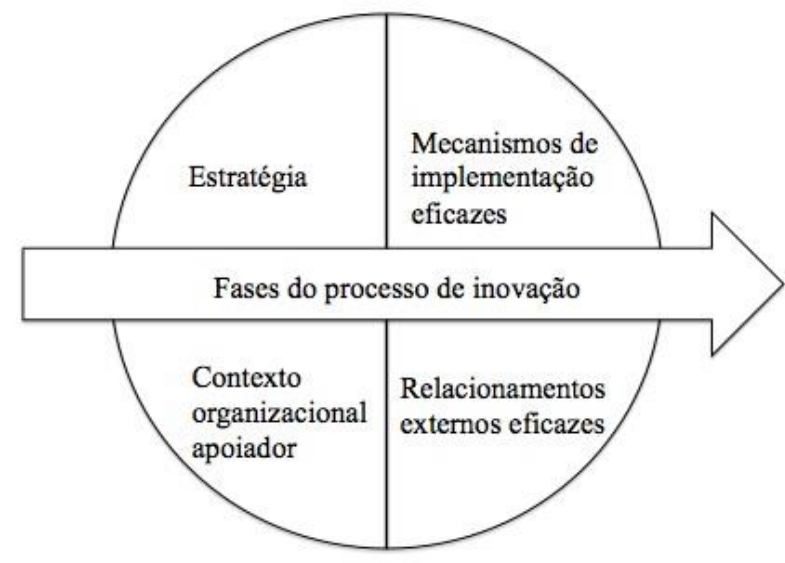

Fonte: Tidd, Bessant e Pavitt (2008)

As fases do processo de inovação, identificadas pela seta na figura, incluem a procura de sinais no ambiente sobre potencial de mudanças, a emergência de oportunidades tecnológicas ou necessidades de mudanças impostas pelo mercado, a seleção do processo de decisão quanto às oportunidades de mudanças e sua adequação à estratégia geral adotada pela organização, a implementação, que reúne as atividades de aquisição de conhecimento, execução do projeto, lançamento e sustentação da inovação e, finalmente, a aprendizagem, que atualiza a competência tecnológica da organização, advinda das lições tecnológicas aprendidas e de melhorias nas capacidades de gestão do processo.

O quadrante superior esquerdo expressa a estratégia, que reúne três componentes essenciais. O primeiro deles é a posição da organização no que diz respeito aos seus produtos, processos e tecnologias. O segundo componente se refere às trajetórias tecnológicas seguidas pela organização e que condicionam, até 
certo ponto, as suas possibilidades de escolhas tecnológicas. Finalmente, o terceiro componente trata dos processos organizacionais, que imprimem o jeito de ser da organização.

O quadrante inferior esquerdo mostra o contexto organizacional apoiador, que envolve a criação de estruturas e acordos de organização do trabalho, treinamento, sistemas de recompensa e reconhecimento, com o objetivo de incentivar 0 surgimento de ideias criativas e sua implantação. O próximo quadrante aponta para os relacionamentos externos eficazes, incluindo entre eles a interação com mercados, fornecedores de tecnologia e outras parcerias, o que oferece oportunidades para a aprendizagem. Finalmente, o último quadrante apresenta os mecanismos de implementação eficazes, os quais referem-se à criação de estruturas de tomada de decisão para a solução sistemática de problemas que permitam alcançar a efetiva concretização da inovação.

Guimarães, Cavalcanti e Affonseca (2004), em pesquisa sobre implementação de inovações gerenciais em organizações públicas, alertam que o processo de inovação tal qual ocorre nas empresas privadas não pode ser transposto, de forma simples e direta, para o ambiente da administração pública, em razão de suas especificidades. Doloreux e Melançon (2008) afirmam que o contexto setorial é importante na potencialização do papel da inovação para a competitividade, fornecendo frameworks que permitem sua avaliação. Destacam ainda a importância dos aspectos relativos à indústria específica, particularmente a intensidade de conhecimento, a localização e o tamanho das firmas.

Com relação à aquisição de conhecimento, que envolve a combinação entre conhecimento existente e novo (disponível dentro e fora da organização) para oferecer soluções para os problemas a serem estudados, o impacto é observado diretamente na capacitação tecnológica das organizações de C\&T. Fatores como o ambiente externo, o ambiente interno e a motivação são importantes para a criação de uma ecologia da inovação que favoreça, por exemplo, a emergência de spin-offs, instrumentos por meio dos quais organizações ampliam sua capacidade inovadora, adensando a cadeia da inovação. Do ponto de vista interno, assume relevância a gestão das competências, particularmente aquelas de alto valor, mais impactantes nas decisões dos gestores e que geram altos ganhos e posicionamento estratégico, principalmente em inovação, conforme afirmam Gonzaga e Muniz Júnior (2016). Além disso, a gestão do conhecimento não pode perder de vista a necessidade de criar e manter condições dentro da organização para que a criatividade possa florescer e contribuir para a inovação eficaz (TIDD; BESSANT; PAVITT, 2008; CONSTANTE; FIALA; ANDREASSI, 2014).

\section{METODOLOGIA}

O trabalho adota uma abordagem qualitativa, empregando como método o estudo de caso. Esse tipo de abordagem aplica-se a estudos que enfocam uma 
realidade bem delimitada, como é o objeto deste estudo, que trata da gestão da inovação em organização de ciência e tecnologia da Marinha do Brasil.

Yin (2001) ressalta que, para o estudo de caso, a coleta de dados deve se basear em várias fontes de evidência, contribuindo, dessa forma, para elevar a confiabilidade do estudo, bem como aumentar a sua validade interna e externa. No presente estudo, além das fontes bibliográficas, incluindo as de natureza empírica, foram utilizados processos de observação direta, por meio de pesquisa de campo, e aplicados questionários a pesquisadores do Centro de Análises de Sistemas Navais (CASNAV) e do Instituto de Pesquisas da Marinha (IPqM), além de uma entrevista aberta com o Assessor de Ciência, Tecnologia e Inovação do referido órgão, para a ampliação e validação de informações. Vale ressaltar que as organizações de C\&T da Marinha, aqui tomadas como referencia, estão entre os mais representativos órgãos científicos e tecnológicos dessa Força.

Foram obtidos 14 questionários com respostas (7 sobre inovação em condição estável e 7 sobre a inovação de ruptura), provenientes de quatro diferentes setores do CASNAV (Departamento de Engenharia de Sistemas; Departamento de Apoio Tecnológico; Assessoria de Gestão Contemporânea; e Assessoria de Inovação Tecnológica), e outros 34 questionários (17 para condição estável e 17 para inovação de ruptura) oriundos de diferentes grupos de trabalho do Departamento de Pesquisas do IPqM.

Os questionários foram desenvolvidos com base no modelo de auditoria dos processos de gestão de inovação propostos por Tidd, Bessant e Pavitt (2008). A auditoria de sistemas de inovação permite que se capture não apenas elementos presentes nos ambientes internos e externos da organização, mas também que se leve em consideração a estrutura de recursos humanos e os seus impactos na performance da organização (BACK, KOVALESKI, ANDRADE JUNIOR, 2014).

A adaptação dos questionários incluiu também a realização prévia de um teste piloto de aplicação. Assim, as respostas aos questionários forneciam elementos para identificar o padrão de comportamento que descreve a maneira como a organização trata a inovação.

A seleção do CASNAV e do IPqM levou em consideração a relevância tecnológica dos respectivos órgãos, responsáveis na Marinha pelo desenvolvimento de sistemas que tem relação com capacidade de combate, comando e controle de navios militares e que constituem importantes áreas de interesse de C\&T naval.

\section{A ESTRUTURA DE CIÊNCIA, TECNOLOGIA E INOVAÇÃO NA MARINHA DO BRASIL}

De Negri (2008) apresenta uma visão geral da formação da estrutura de Ciência, Tecnologia e Inovação da Marinha. O processo inicia em 1995 com a criação da Secretaria-Executiva do Conselho de Ciência e Tecnologia da Marinha (SECONCITEM), cujo propósito era de apoiar administrativamente os órgãos 
colegiados encarregados de elaborar, acompanhar e supervisionar a execução do Plano de Desenvolvimento Científico e Tecnológico da Marinha (PDCTM).

A SECONCITEM foi extinta em 2002, passando suas tarefas à responsabilidade da Divisão de C\&T do Estado-Maior da Armada (EMA). Em 2008, foi criada a Secretaria de Ciência, Tecnologia e Inovação da Marinha (SecCTM), com sede em Brasília, como resultado de estudos anteriores. O objetivo era dar à SecCTM a condição de órgão central executivo do Sistema de Ciência e Tecnologia da Marinha (SCTM), exercendo o planejamento, a orientação, a coordenação e o controle das atividades de CT\&I, com tarefas definidas no Quadro 1 (DE NEGRI, 2008, p. 10).

Quadro 1 - Plano de trabalho da SecCTM

ATIVIDADES A SEREM CUMPRIDAS PELA SecCTM

Exercer a Coordenação do Sistema de Ciência e Tecnologia da Marinha (SCTM)

Efetuar a administração estratégica de CT\&I

Acompanhar a evolução científica e tecnológica, o estado da arte e os trabalhos de pesquisa e desenvolvimento realizados em instituições privadas e governamentais, nos assuntos de interesse da Marinha

Elaborar, revisar e submeter ao EMA as alterações e atualizações do PDCTM

Identificar e obter fontes alternativas de recursos extra orçamentários para as atividades de CT\&I

Manter intercâmbio com as demais Forças e com os setores industrial, universitário e técnico-científicos nas atividades de pesquisa científica e desenvolvimento tecnológico de sistemas, de equipamentos, de componentes, de materiais e de técnicas de interesse da Marinha

Fonte: Adaptado de De Negri (2008)

Com a criação da SecCTM, três órgãos voltados essencialmente para C\&T passaram à sua subordinação: (i) IPqM - Instituto de Pesquisas da Marinha, Ilha do Governador, Rio de Janeiro; (ii) CASNAV - Centro de Análises de Sistemas Navais, Ilha das Cobras, Rio de Janeiro; (iii) IEAPM - Instituto de Estudos do Mar Almirante Paulo Moreira, Arraial do Cabo (RJ).

Além dos três órgãos de C\&T citados, existe ainda o Centro Tecnológico da Marinha em São Paulo (CTMSP), também integrante do SCTM, porém subordinado à Diretoria-Geral do Material da Marinha (DGMM), que fica sediado no campus da Universidade de São Paulo (USP), com instalações também em Iperó (SP), onde funciona o Centro Experimental Aramar (CEA).

Cada um dos citados órgãos de C\&T tem áreas de atuação e competências diversas. O IPqM atua nas áreas de Armas, Guerra Eletrônica, Sistemas Sonar, Sistemas Digitais, Materiais e Sistemas Inerciais. O CASNAV realiza trabalhos de análise e desenvolvimento de sistemas nas áreas de Pesquisa Operacional, Análise de Sistemas, Engenharia de Sistemas, Informática, Criptologia, dentre outros. O 
IEAPM atua nas áreas de Oceanografia, Meteorologia, Hidrografia, Geologia e Geofísica Marinhas, Instrumentação Oceanográfica, Acústica Submarina e Engenharia Costeira e Oceânica. O CTMSP dedica-se à pesquisa e desenvolvimento de sistemas nucleares e energéticos para emprego em sistemas de propulsão de navios da Marinha, atuando no desenvolvimento de sistemas térmicos, químicos e eletromecânicos, e no projeto, fabricação e testes de componentes.

Em 2011, como parte das ações desenvolvidas pela SecCTM em direção ao estabelecimento de intercâmbios, foram firmados Acordos de Cooperação Acadêmica, Técnica e Científica com a Universidade Federal Fluminense (UFF), com a Universidade Federal do Rio de Janeiro (UFRJ) e com a Pontifícia Universidade Católica do Rio de Janeiro (PUC-Rio).

\section{AUDITORIA DA GESTÃO DA INOVAÇÃO E DISCUSSÃO DOS RESULTADOS}

O modelo de auditoria da inovação utilizado consiste em uma lista de questões, apresentadas no Quadro 2, cujas respostas visam identificar o padrão de comportamento que descreve como a organização trata a inovação em sua condição estável. Os autores destacam, como aspecto mais importante dessa ferramenta, a possibilidade de ser utilizada para permitir uma investigação dos fatores que afetam o sucesso da inovação e de como a gestão do processo deve ser melhorada.

Assim como a auditoria tecnológica, a auditoria da inovação vai além de simplesmente identificar falhas no processo e possibilidades de melhoria. Como afirmam Back et al (2014), a auditoria permite levantar as informações relevantes relacionadas à tecnologia permitindo, dessa forma, determinar-se o nível tecnológico, ou seja a capacidade da empresa em adotar tecnologias novas em relação a sua complexidade. No caso das organizações militares de pesquisa, esta condição é particularmente importante porque, em se tratando de defesa nacional, a referencia é sempre global e a complexidade é crescente.

As questões formuladas enfocam fatores ou comportamentos que contemplam, segundo os mesmos autores, rotinas importantes para se ter um bom desempenho em gestão da inovação, que são agrupadas nos seguintes componentes: Estratégia, Relacionamentos Eficazes, Organização Inovadora, Processos Organizacionais e Aprendizagem. 
Quadro 2 - Questionário para Auto-Avaliação da Gestão da Inovação na Condição Estável QUÃO BEM É GERENCIADA A INOVAÇÃO NESTA ORGANIZAČ̃̃O.

As afirmações abaixo apresentam o padrão de comportamento existente na Organização que descreve como o processo de inovação é tratado. Para cada afirmação, atribua uma pontuação entre 1 (totalmente falso) e 7 (muito verdadeiro).

\begin{tabular}{|l|l|}
\hline Afirmação & Pontuação \\
\hline $\begin{array}{l}\text { 1. Nossa equipe tem uma visão compartilhada de como a Organização se } \\
\text { desenvolverá por meio da inovação. }\end{array}$ & \\
\hline $\begin{array}{l}\text { 2. Nossa estrutura de organização não reprime a inovação, mas favorece sua } \\
\text { ocorrência. }\end{array}$ & \\
\hline $\begin{array}{l}\text { 3. Há um forte comprometimento com treinamento e desenvolvimento de } \\
\text { pessoas. }\end{array}$ & \\
\hline $\begin{array}{l}\text { 4. Nossa estratégia de inovação é expressa de maneira clara; assim, todos } \\
\text { conhecem as metas de melhoria. }\end{array}$ & \\
\hline $\begin{array}{l}\text { 5. Nossos projetos de inovação geralmente são realizados no prazo e dentro de } \\
\text { orçamento. }\end{array}$ & \\
\hline 6. As pessoas trabalham bem em conjunto além dos limites departamentais. & \\
\hline $\begin{array}{l}\text { 7. Somos bons em compreender as necessidades de nossos clientes / usuários } \\
\text { finais. }\end{array}$ & \\
\hline $\begin{array}{l}\text { 8. Trabalhamos bem com universidades e outros centros de pesquisa para ajudar } \\
\text { a desenvolver nosso conhecimento. }\end{array}$ & \\
\hline $\begin{array}{l}\text { 9. Olhamos para frente, em um caminho estruturado (utilizando ferramentas e } \\
\text { técnicas de previsão), para tentar e imaginar futuras ameaças e oportunidades. }\end{array}$ & \\
\hline $\begin{array}{l}\text { 10. Possuímos mecanismos eficazes para gerenciar a mudança de processo, } \\
\text { desde a ideia até a implementação bem-sucedida. }\end{array}$ & \\
\hline $\begin{array}{l}\text { 11. A comunicação é eficaz e funciona de cima para baixo, de baixo para cima e } \\
\text { através da organização. }\end{array}$ & \\
\hline $\begin{array}{l}\text { 12. Reunimo-nos e compartilhamos experiências com outras empresas ou } \\
\text { organizações para que nos ajudem a aprender. }\end{array}$ & \\
\hline $\begin{array}{l}\text { 13. Tentamos desenvolver redes de contato externas com pessoas que podem } \\
\text { nos ajudar - por exemplo, pessoas com conhecimento especializado. }\end{array}$ & \\
\hline $\begin{array}{l}\text { 14. Existe flexibilidade suficiente em nosso sistema de desenvolvimento de } \\
\text { produto para permitir que pequenos projetos "rápidos" aconteçam. }\end{array}$ & \\
\hline $\begin{array}{l}\text { 15. Usamos mensurações para ajudar a identificar onde e quando podemos } \\
\text { melhorar nossa gestão da inovação. }\end{array}$ & \\
\hline $\begin{array}{l}\text { Caso deseje, você poderá apresentar comentários considerados relevantes a respeito do } \\
\text { questionário ou sobre a inovação na Organização. }\end{array}$ & \\
\hline & \\
\hline
\end{tabular}

Fonte: Adaptado de Tidd, Bessant e Pavitt (2008)

As pontuações relativas aos questionários respondidos para a auto-avaliação na condição estável, no caso do CASNAV, estão apresentadas na Tabela 1. 
Tabela 1 - Respostas aos questionários no CASNAV - Inovação na Condição Estável

\begin{tabular}{|c|c|c|c|c|c|c|c|c|c|c|c|c|c|}
\hline \multicolumn{9}{|c|}{$\begin{array}{l}\text { CASNAV - CENTRO DE ANALISES DE SISTEMAS } \\
\text { NAVAIS }\end{array}$} & \multirow{3}{*}{ 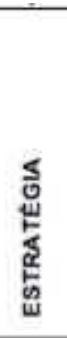 } & \multirow{3}{*}{ 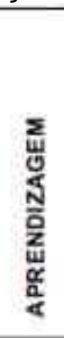 } & \multirow{3}{*}{ 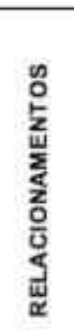 } & \multirow{3}{*}{ 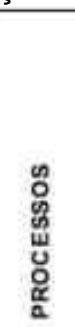 } & \multirow{3}{*}{ 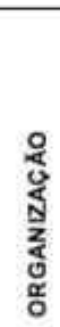 } \\
\hline \multicolumn{9}{|c|}{$\begin{array}{l}\text { QUESTIONARIO - QUUAO BEM E GERENCIADA A INOVAÇAO NESTA } \\
\text { ORGANIZAÇAO (CONDICQAO ESTAVEL) }\end{array}$} & & & & & \\
\hline QUESTAOO & \multicolumn{7}{|c|}{ QUESTIONARIOS RESPONDIDOS } & MÉDIAS & & & & & \\
\hline 1 & 5 & 5 & 5 & 7 & 4 & 5 & 5 & 5,1 & 5,1 & & & & \\
\hline 2 & 4 & 6 & 7 & 7 & 6 & 6 & 7 & 6,1 & & & & & 6,1 \\
\hline 3 & 6 & 7 & 6 & 7 & 7 & 7 & 7 & 6.7 & & 6,7 & & & \\
\hline 4 & 4 & 5 & 5 & 6 & 4 & 5 & 6 & 5,0 & 5,0 & & & & \\
\hline 5 & 5 & 6 & 4 &. & 4 & 6 & 8 & 5,2 & & & & 5.2 & \\
\hline 6 & 5 & 5 & 6 & 7 & 7 & 4 & 8 & 5,7 & & & & & 5.7 \\
\hline 7 & 7 & 5 & 6 & 7 & 6 & 7 & 7 & 6,4 & & & 6,4 & & \\
\hline$\theta$ & 5 & 5 & 7 & 7 & 5 & 6 & 8 & 5.9 & & & 5,9 & & \\
\hline 9 & 5 & 4 & 5 & 7 & 4 & 7 & 8 & 5,4 & 5,4 & & & & \\
\hline 10 & 7 & 4 & 5 & 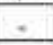 & 4 & 8 & 7 & 5,5 & & & & 5,5 & \\
\hline 11 & 6 & 4 & 6 & 7 & 8 & 6 & 7 & 6,0 & & & & & 6,0 \\
\hline 12 & 7 & 4 & 6 & 7 & 4 & 5 & 8 & 5,6 & & 5,6 & & & \\
\hline 13 & 6 & 6 & 7 & 7 & 5 & 6 & 6 & 6,1 & & & 6,1 & & \\
\hline 14 & 2 & 6 & 6 & 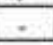 & 4 & 5 & 4 & 4,5 & & & & 4,5 & \\
\hline 15 & 7 & 4 & 6 & . & 6 & 7 & 5 & 5,8 & & 5,8 & & & \\
\hline \multicolumn{9}{|c|}{ MÉDIAS FINAIS } & 5,2 & 6,0 & 6,1 & 5,1 & 6,0 \\
\hline
\end{tabular}

Fonte: Elaborada Pelos Autores

O gráfico da Figura 2 ilustra o desempenho resultante das pontuações obtidas pelo CASNAV para a inovação na condição estável.

Figura 2 - Desempenho do CASNAV na inovação na Condição Estável

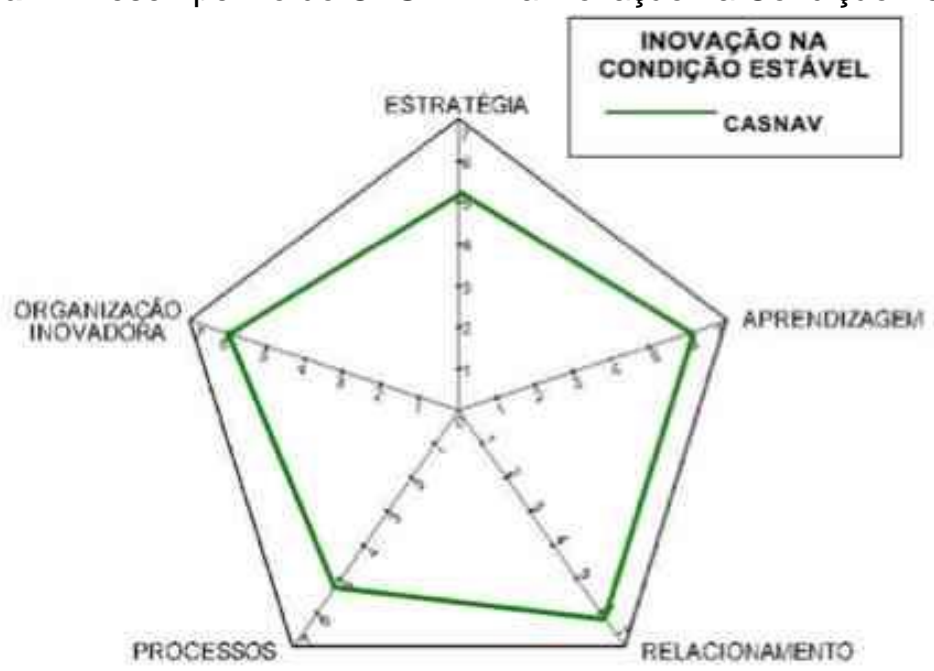

Fonte: Elaborada pelos autores

Conforme mostrado na Tabela 1 e na Figura 2, em termos de inovação na condição estável, as pontuações médias obtidas pelo CASNAV situaram-se entre os valores de 5,1 e 6,1, numa escala máxima de 7, com melhor avaliação no que se refere aos fatores ligados a Relacionamentos Eficazes $(6,1)$ e menor desempenho 
nos aspectos ligados a Processos Organizacionais $(5,1)$, seguido por Estratégia $(5,2)$.

Um comentário oferecido no questionário, referente à inovação na condição estável, considera que "a cultura da inovação ainda está se desenvolvendo na organização. Somos excelência em desenvolvimento de softwares, mas, estamos ampliando as nossas relações com Institutos de Pesquisa e Universidades de modo a criarmos um ambiente organizacional mais propício à inovação". Desse modo, observa-se que existe, de fato, uma "cultura da inovação" em progresso no CASNAV, o que é também identificado pela satisfatória pontuação obtida, não havendo nenhum desnível mais acentuado em relação à nenhum dos componentes estruturantes do gráfico.

Mesmo considerando o satisfatório desempenho do CASNAV identificado pela pontuação obtida, cabe ainda destacar o pensamento de Tidd, Bessant e Pavitt (2008, p. 588), segundo o qual "não há algo como uma organização perfeita para a gestão da inovação; sempre haverá oportunidades para experimentação e melhorias contínuas".

Passando-se à auto-avaliação do IPqM, foram obtidos desta organização 17 questionários, oriundos de diferentes grupos de trabalho do seu Departamento de Pesquisas. As pontuações correspondentes aos questionários respondidos para a auto-avaliação na condição estável estão apresentadas na Tabela 2, a seguir.

Tabela 2 - Respostas aos Questionários no IPqM - Inovação na Condição Estável

\begin{tabular}{|c|c|c|c|c|c|c|c|c|c|c|c|c|c|c|c|c|c|c|c|c|}
\hline \multicolumn{16}{|c|}{ IPqM - INSTITUTO DE PESQUISAS DA MARINHA } & \multirow{3}{*}{ 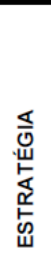 } & \multirow{3}{*}{ 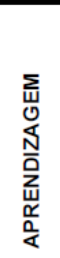 } & \multirow{3}{*}{ 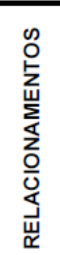 } & \multirow{3}{*}{ 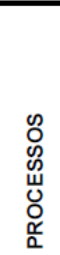 } & \multirow{3}{*}{$\begin{array}{l}\text { \& } \\
\text { U } \\
\mathbb{N} \\
\text { z } \\
0 \\
0 \\
0 \\
0\end{array}$} \\
\hline \multicolumn{5}{|c|}{$\begin{array}{l}\text { QUESTIONÁRIO - QUÃO } \\
\text { (CONDIÇÃO ESTÁVEL) }\end{array}$} & \multicolumn{2}{|c|}{ BEM É } & \multicolumn{3}{|c|}{ GERENCIADA } & \multicolumn{3}{|c|}{ A A INOVAÇÃO } & NESTA & \multicolumn{2}{|c|}{ ORGANIZAÇÄO } & & & & & \\
\hline QUESTÃO & & & \begin{tabular}{|l|}
3 \\
\end{tabular} & 4 & 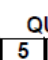 & $\begin{array}{l}\text { UES } \\
6\end{array}$ & TION & $\mid$ & \begin{tabular}{l} 
OS RE \\
\multicolumn{2}{|l|}{$\mid$} \\
9
\end{tabular} & $\begin{array}{l}\text { ESPONL } \\
10|11|\end{array}$ & & & \begin{tabular}{|l|l|}
14 & $15 \mid$
\end{tabular} & \begin{tabular}{|l|l|}
16 & 1 \\
\end{tabular} & 7 MÉDIAS & & & & & \\
\hline 1 & \begin{tabular}{|l|}
5 \\
\end{tabular} & \begin{tabular}{l|l}
6 \\
\end{tabular} & \begin{tabular}{|l|}
3 \\
\end{tabular} & \begin{tabular}{|l|}
2 \\
\end{tabular} & \begin{tabular}{|l|}
2 \\
\end{tabular} & 4 & 4 & \begin{tabular}{|l|l}
5 & \\
\end{tabular} & \begin{tabular}{|l|l}
5 & 5 \\
\end{tabular} & \begin{tabular}{|l|l|}
5 & 1 \\
\end{tabular} & 4 & \begin{tabular}{l|l}
2 & 2 \\
\end{tabular} & \begin{tabular}{|l|l|}
2 & 1 \\
\end{tabular} & \begin{tabular}{|l|l|}
3 & 1 \\
\end{tabular} & 3,2 & 3,2 & & & & \\
\hline 2 & \begin{tabular}{|l|}
5 \\
\end{tabular} & 5 & \begin{tabular}{|l|}
3 \\
\end{tabular} & \begin{tabular}{|l|l|}
2 & \\
\end{tabular} & \begin{tabular}{|l|}
2 \\
2
\end{tabular} & 4 & 4 & \begin{tabular}{|l|l|}
4 & \\
\end{tabular} & \begin{tabular}{|l|l|}
5 & 5 \\
\end{tabular} & \begin{tabular}{|l|l|}
5 & 3 \\
\end{tabular} & 5 & \begin{tabular}{|l|l|l|}
4 & 3 \\
\end{tabular} & \begin{tabular}{|l|l|}
3 & 4 \\
\end{tabular} & \begin{tabular}{|l|l|}
2 & 2 \\
\end{tabular} & 3,6 & & & & & 3,6 \\
\hline 3 & \begin{tabular}{|l|}
5 \\
\end{tabular} & 5 & \begin{tabular}{|l|}
2 \\
\end{tabular} & 2 & \begin{tabular}{|l|}
2 \\
\end{tabular} & 4 & 4 & 4 & \begin{tabular}{|l|l}
4 & 5 \\
\end{tabular} & \begin{tabular}{|l|l|}
5 & 3 \\
\end{tabular} & 3 & \begin{tabular}{|l|l|}
2 & 5 \\
\end{tabular} & \begin{tabular}{|l|l|}
5 & 4 \\
\end{tabular} & \begin{tabular}{|l|l|}
2 & 2 \\
\end{tabular} & 3,4 & & 3,4 & & & \\
\hline 4 & \begin{tabular}{|l|}
2 \\
\end{tabular} & \begin{tabular}{|l|}
5 \\
\end{tabular} & \begin{tabular}{|l|}
- \\
\end{tabular} & 2 & \begin{tabular}{|l|}
1 \\
\end{tabular} & 4 & 3 & \begin{tabular}{|l|}
1 \\
\end{tabular} & \begin{tabular}{|l|l|}
4 & 4 \\
\end{tabular} & \begin{tabular}{|l|l|}
4 & 1 \\
\end{tabular} & 4 & \begin{tabular}{|l|l}
1 & 2 \\
\end{tabular} & \begin{tabular}{l|l|}
2 & 1 \\
\end{tabular} & \begin{tabular}{|l|l|}
2 & 2 \\
\end{tabular} & 2,4 & 2,4 & & & & \\
\hline 5 & \begin{tabular}{|l|l|}
5 \\
\end{tabular} & \begin{tabular}{|l|}
3 \\
\end{tabular} & \begin{tabular}{|l|}
3 \\
\end{tabular} & 2 & \begin{tabular}{|l|}
1 \\
\end{tabular} & 3 & 2 & \begin{tabular}{|l|l|}
3 & \\
\end{tabular} & \begin{tabular}{|l|l|}
6 & 5 \\
\end{tabular} & \begin{tabular}{|l|l|}
5 & 2 \\
\end{tabular} & 4 & \begin{tabular}{|l|l|}
2 & 2 \\
\end{tabular} & \begin{tabular}{l|l}
2 & 1 \\
\end{tabular} & \begin{tabular}{|l|l|}
4 & 2 \\
\end{tabular} & 2,9 & & & & 2,9 & \\
\hline 6 & 2 & \begin{tabular}{|l|}
5 \\
\end{tabular} & \begin{tabular}{|l|}
3 \\
\end{tabular} & 3 & \begin{tabular}{|l|}
3 \\
\end{tabular} & 4 & 5 & \begin{tabular}{|l|}
2 \\
\end{tabular} & \begin{tabular}{|l|l}
4 & 5 \\
\end{tabular} & \begin{tabular}{|l|l|}
5 & 1 \\
\end{tabular} & 6 & \begin{tabular}{|l|l}
3 & 3 \\
\end{tabular} & \begin{tabular}{l|l}
3 & 7 \\
\end{tabular} & \begin{tabular}{|l|l|}
5 & 1 \\
\end{tabular} & 3,6 & & & & & 3,6 \\
\hline 7 & \begin{tabular}{|l|}
3 \\
\end{tabular} & \begin{tabular}{|l|}
4 \\
\end{tabular} & 5 & 3 & \begin{tabular}{|l|}
3 \\
\end{tabular} & 6 & 4 & \begin{tabular}{|l|}
5 \\
\end{tabular} & \begin{tabular}{|l|l|}
7 & 6 \\
\end{tabular} & \begin{tabular}{|l|l|}
6 & 4 \\
\end{tabular} & \begin{tabular}{|l|}
6 \\
\end{tabular} & \begin{tabular}{|l|l|}
4 & 7 \\
\end{tabular} & \begin{tabular}{l|l|}
7 & 6 \\
\end{tabular} & \begin{tabular}{|l|l|}
6 & 1 \\
\end{tabular} & 4,7 & & & 4,7 & & \\
\hline 8 & \begin{tabular}{|l|l|}
5 \\
\end{tabular} & \begin{tabular}{|l|}
6 \\
\end{tabular} & \begin{tabular}{|l|}
3 \\
\end{tabular} & 4 & \begin{tabular}{|l|}
3 \\
\end{tabular} & 3 & 4 & \begin{tabular}{|l|l|}
6 & \\
\end{tabular} & \begin{tabular}{|l|l|}
5 & 5 \\
\end{tabular} & \begin{tabular}{|l|l|}
5 & 3 \\
\end{tabular} & 5 & \begin{tabular}{|l|l}
2 & 2 \\
\end{tabular} & \begin{tabular}{|l|l|}
4 & 6 \\
\end{tabular} & \begin{tabular}{|l|l|}
7 & 5 \\
\end{tabular} & 4,5 & & & 4,5 & & \\
\hline 9 & 2 & \begin{tabular}{|l|}
4 \\
\end{tabular} & \begin{tabular}{|l|}
3 \\
\end{tabular} & 1 & \begin{tabular}{|l|}
3 \\
\end{tabular} & 3 & 3 & 1 & \begin{tabular}{|l|l|}
4 & 4 \\
\end{tabular} & \begin{tabular}{|l|l|}
4 & 2 \\
\end{tabular} & 4 & \begin{tabular}{|l|l}
2 & 3 \\
\end{tabular} & \begin{tabular}{l|l}
3 & 1 \\
\end{tabular} & \begin{tabular}{|l|l|}
5 & 2 \\
\end{tabular} & 2,8 & 2,8 & & & & \\
\hline 10 & 2 & 2 & \begin{tabular}{|l|}
2 \\
\end{tabular} & 3 & \begin{tabular}{|l|}
3 \\
\end{tabular} & 3 & 3 & \begin{tabular}{|l|l|}
3 \\
\end{tabular} & \begin{tabular}{|l|l|}
4 & 4 \\
\end{tabular} & \begin{tabular}{|l|l|}
4 & 2 \\
\end{tabular} & 4 & \begin{tabular}{|l|l|}
2 & 5 \\
\end{tabular} & \begin{tabular}{l|l}
5 & 2 \\
\end{tabular} & \begin{tabular}{|l|l|}
2 & 2 \\
\end{tabular} & 2,8 & & & & 2,8 & \\
\hline 11 & 5 & \begin{tabular}{|l|l|}
3 \\
\end{tabular} & \begin{tabular}{|l|l|}
3 \\
\end{tabular} & 5 & \begin{tabular}{|l|}
5 \\
\end{tabular} & 5 & 3 & \begin{tabular}{|l|l|}
4 & \\
\end{tabular} & \begin{tabular}{|l|l|}
4 & 4 \\
\end{tabular} & \begin{tabular}{|l|l|}
4 & 2 \\
\end{tabular} & 5 & \begin{tabular}{|l|l|l|}
3 & 3 \\
\end{tabular} & \begin{tabular}{|l|l|}
3 & 5 \\
\end{tabular} & \begin{tabular}{|l|l|}
3 & 2 \\
\end{tabular} & 3,8 & & & & & 3,8 \\
\hline 12 & 2 & \begin{tabular}{|l|}
5 \\
\end{tabular} & \begin{tabular}{|l|}
2 \\
\end{tabular} & 2 & \begin{tabular}{|l|}
2 \\
\end{tabular} & 3 & 4 & 4 & \begin{tabular}{l|l}
3 & 5 \\
\end{tabular} & \begin{tabular}{|l|l|}
5 & 2 \\
\end{tabular} & 5 & \begin{tabular}{l|l}
2 & 4 \\
\end{tabular} & \begin{tabular}{|l|l}
4 & 3 \\
\end{tabular} & \begin{tabular}{|l|l|}
3 & 2 \\
\end{tabular} & 3,1 & & 3,1 & & & \\
\hline 13 & 4 & 6 & \begin{tabular}{|l|}
3 \\
\end{tabular} & 5 & 5 & 4 & 4 & 5 & \begin{tabular}{l|l}
5 & 7 \\
\end{tabular} & \begin{tabular}{|l|l|}
7 & 4 \\
\end{tabular} & 6 & \begin{tabular}{l|l}
3 & 3 \\
\end{tabular} & \begin{tabular}{|l|l|}
3 & 4 \\
\end{tabular} & \begin{tabular}{|l|l|}
5 & 4 \\
\end{tabular} & 4,5 & & & 4,5 & & \\
\hline 14 & 4 & \begin{tabular}{|l|}
2 \\
\end{tabular} & \begin{tabular}{|l|}
5 \\
\end{tabular} & \begin{tabular}{|l|}
1 \\
\end{tabular} & \begin{tabular}{|l|}
1 \\
\end{tabular} & 3 & 3 & \begin{tabular}{|l|}
5 \\
\end{tabular} & \begin{tabular}{l|l}
5 & 4 \\
\end{tabular} & \begin{tabular}{|l|l|}
4 & 4 \\
\end{tabular} & 3 & \begin{tabular}{l|l}
4 & 4 \\
\end{tabular} & \begin{tabular}{|l|l|}
4 & 1 \\
\end{tabular} & \begin{tabular}{|l|l|}
3 & 2 \\
\end{tabular} & 3,2 & & & & 3,2 & \\
\hline 15 & \begin{tabular}{|l|}
2 \\
\end{tabular} & \begin{tabular}{|l|}
2 \\
\end{tabular} & \begin{tabular}{|l|}
1 \\
\end{tabular} & 1 & \begin{tabular}{|l|}
1 \\
\end{tabular} & 3 & 3 & \begin{tabular}{|l|l}
1 & \\
\end{tabular} & \begin{tabular}{l|l}
3 & 4 \\
\end{tabular} & \begin{tabular}{|l|l|}
4 & 1 \\
\end{tabular} & 3 & \begin{tabular}{l|l}
2 & 2 \\
\end{tabular} & \begin{tabular}{l|l|}
2 & 1 \\
\end{tabular} & \begin{tabular}{|l|l|}
3 & 2 \\
\end{tabular} & 2,1 & & \begin{tabular}{|l|}
2,1 \\
\end{tabular} & & & \\
\hline & & & & & & & & & & & & & & & $\begin{array}{l}\text { MÉDIAS } \\
\text { FINAIS }\end{array}$ & 2,8 & 2,9 & 4,6 & 3,0 & 3,7 \\
\hline
\end{tabular}

Fonte: Elaborada pelos autores

O gráfico da Figura 3, a seguir, ilustra o desempenho resultante das pontuações obtidas pelo IPqM para a inovação na condição estável. 
Figura 3 - Desempenho do IPqM na Inovação na Condição Estável

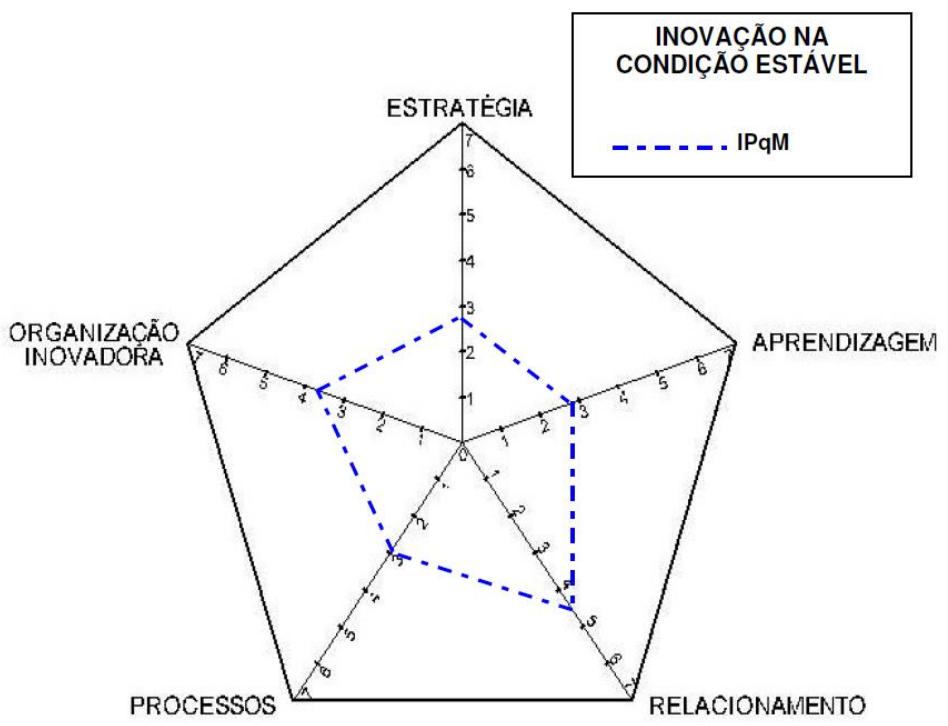

Fonte: Elaborada pelos autores

Conforme mostrado na Tabela 2 e na Figura 3, em termos de inovação na condição estável, as pontuações médias obtidas pelo IPqM situaram-se em patamares inferiores ao do CASNAV, entre o valor máximo de 4,6 (em Relacionamentos Eficazes) e mínimo de 2,8 (em Estratégia). Apresentaram pontuações mais baixas as componentes Aprendizagem (2,9) e Processos Organizacionais $(3,0)$ e, em situação intermediária, Organização Inovadora $(3,7)$.

Os questionários recebidos do IPqM apresentaram dispersão elevada, o que sinaliza diversidade significativa de opiniões entre os pesquisadores dessa organização, tornando mais precária a utilização da média como indicador. Há, nitidamente, uma perspectiva mais crítica com relação à cultura local de inovação, indicando, ou a existência de nichos com diferentes graus de articulação inovadora, ou uma baixa circulação da informação, com reflexo na disseminação e difusão de inovação. Olhando de uma perspectiva mais otimista, os resultados, até mesmo por sua tonalidade crítica e autocrítica, parecem, por outro lado, apontar para a existência de uma das condições capacitadoras do ambiente inovador, tal como definido por Takeuchi e Nonaka (2008), que é a autonomia.

Esse diagnóstico encontra eco em afirmações pontuais, tais como a do pesquisador que declara que "existe a necessidade de maior comunicação entre os setores da organização para promover a troca de conhecimento, como também, a necessidade de uma maior interação com as outras organizações visando a troca de experiências", além de outro que informa desconhecer "ferramentas e técnicas para gestão de inovação que sejam utilizadas pela organização".

De forma análoga aos questionários para avaliação da inovação em condição estável, Tidd, Bessant e Pavitt (2008) propõem semelhante abordagem para a inovação de ruptura. Para os autores, existem condições - além da condição estável 
- em que são necessárias sistemáticas diversas para gerenciar a inovação e introduzir rotinas novas ou complementares àquelas para lidar com a inovação na condição estável. O Quadro 3 contém questões que visam mostrar o padrão de comportamento da organização em inovação de ruptura.

Quadro 3 - Questionário para Auto-Avaliação da Gestão da Inovação de Ruptura

\begin{tabular}{|c|c|}
\hline $\begin{array}{l}\text { QUÃO BEM É GERENCIADA A INOVAÇÃO DE RUPTURA } \\
\text { NESTA ORGANIZAÇ̃̃O. } \\
\text { Para cada afirmação, atribua uma pontuação entre } 1 \text { (totalmente falso) e } \\
\text { verdadeiro). }\end{array}$ & 7 (muito \\
\hline Afirmação & Pontuação \\
\hline $\begin{array}{l}\text { 1. Empregamos abordagens de "investigar e aprender" para explorar novas } \\
\text { direções em tecnologias e mercados. }\end{array}$ & \\
\hline $\begin{array}{l}\text { 2. Exploramos prospectivamente o futuro, usando ferramentas e técnicas como } \\
\text { cenários e previsões. }\end{array}$ & \\
\hline $\begin{array}{l}\text { 3. Nossa organização oferece espaço e tempo para as pessoas explorarem } \\
\text { ideias inusitadas. }\end{array}$ & \\
\hline 4. Usamos técnicas formais para procurar e aprender fora de nosso setor. & \\
\hline 5. Focamos "práticas inovadoras", bem como "melhores práticas". & \\
\hline $\begin{array}{l}\text { 6. Utilizamos alguma forma de sondagem tecnológica/coleta de inteligência - } \\
\text { possuímos antenas de tecnologia bem-desenvolvidas. }\end{array}$ & \\
\hline $\begin{array}{l}\text { 7. Possuímos relacionamentos amplos com um grande espectro de fontes } \\
\text { externas de conhecimento - universidades, centros de pesquisa, agências } \\
\text { especializadas - e os mantemos possuindo ou não projetos específicos. }\end{array}$ & \\
\hline $\begin{array}{l}\text { 8. Possuímos sistemas de recompensa para estimular as pessoas a oferecer suas } \\
\text { ideias. }\end{array}$ & \\
\hline $\begin{array}{l}\text { 9. Utilizamos tecnologia que nos ajuda a ser mais ágeis e rápidos na } \\
\text { conscientização e resposta a ameaças emergentes e oportunidades periféricas. }\end{array}$ & \\
\hline $\begin{array}{l}\text { 10. Possuímos sistemas de "alerta" para gerar avisos antecipados sobre novas } \\
\text { tendências para o processo de tomada de decisão estratégico. }\end{array}$ & \\
\hline $\begin{array}{l}\text { 11. Possuímos mecanismos de tomada de decisão estratégica e seleção de } \\
\text { projeto que podem lidar com propostas mais radicais, fora dos padrões } \\
\text { regulares. }\end{array}$ & \\
\hline $\begin{array}{l}\text { 12. Há flexibilidade suficiente em nosso sistema para o desenvolvimento de } \\
\text { produto, permitindo que projetos pequenos e simples aconteçam. }\end{array}$ & \\
\hline 13. A experimentação é estimulada. & \\
\hline $\begin{array}{l}\text { 14. Reconhecemos os usuários como fontes de novas ideias e tentamos "co- } \\
\text { envolver" novos produtos e serviços destinados a eles. }\end{array}$ & \\
\hline $\begin{array}{l}\text { 15. Desafiamo-nos regularmente para identificar onde e quando podemos } \\
\text { melhorar nossa gestão da inovação. }\end{array}$ & \\
\hline $\begin{array}{l}\text { Caso deseje, você poderá apresentar comentários considerados relevantes a } \mathrm{r} \\
\text { questionário ou sobre a inovação na Organização. }\end{array}$ & speito do \\
\hline
\end{tabular}

Fonte: Adaptado de Tidd, Bessant e Pavitt (2008)

Revista Produção Online, Florianópolis, SC, v. 16, n. 4, p. 1371-1392, out./dez. 2016. 
Foram obtidos sete questionários com respostas do CASNAV de autoavaliação da inovação de ruptura, das mesmas pessoas que responderam aos questionários referentes à inovação na condição estável. As pontuações pertinentes aos questionários respondidos para a inovação de ruptura estão apresentadas na Tabela 3.

Tabela 3 - Respostas aos questionários CASNAV - Inovação de Ruptura

\begin{tabular}{|c|c|c|c|c|c|c|c|c|c|c|c|c|c|}
\hline \multicolumn{9}{|c|}{$\begin{array}{l}\text { CASNAV - CENTRO DE ANALISES DE SISTEMAS } \\
\text { NAVAIS }\end{array}$} & \multirow{4}{*}{ 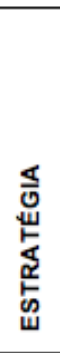 } & \multirow{4}{*}{ 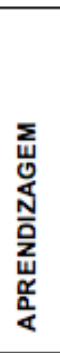 } & \multirow{4}{*}{ 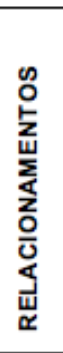 } & \multirow{4}{*}{ 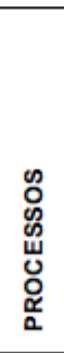 } & \multirow{4}{*}{ 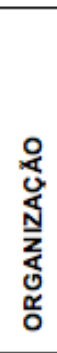 } \\
\hline \multicolumn{9}{|c|}{$\begin{array}{l}\text { QUESTIONÁRIO - QUÃO BEM É GERENCIADA A INOVAÇÃO DE } \\
\text { RUPTURA NESTA ORGANIZAÇÁOO }\end{array}$} & & & & & \\
\hline \multirow{2}{*}{ QUESTÃO } & \multicolumn{7}{|c|}{ QUESTIONARIOS RESPONDIDOS } & \multirow[b]{2}{*}{ MÉDIAS } & & & & & \\
\hline & 1 & 2 & 3 & 4 & 5 & 6 & 7 & & & & & & \\
\hline 1 & 4 & 4 & 7 & 5 & 2 & 6 & 5 & 4,3 & 4,3 & & & & \\
\hline 2 & 4 & 3 & 6 & 4 & 3 & 6 & 5 & 4,1 & & & & 4,1 & \\
\hline 3 & 3 & 3 & 7 & 3 & 2 & 6 & 4 & 3,9 & & & & & 3,9 \\
\hline 4 & 3 & 4 & 5 & - & 3 & 4 & 5 & 4,0 & & 4,0 & & & \\
\hline 5 & 4 & 5 & 6 & 4 & 4 & 6 & 6 & 5,0 & & & 5,0 & & \\
\hline 6 & 4 & 4 & 1 & 4 & 1 & 5 & 5 & 3,8 & & & & 3,8 & \\
\hline 7 & 6 & 6 & 7 & 7 & 3 & 5 & 6 & 5,9 & & & 5,9 & & \\
\hline 8 & 1 & 3 & 4 & 1 & 3 & 6 & 2 & 3,5 & & & & & 3,5 \\
\hline 9 & 4 & 3 & 1 & 1 & 2 & 6 & 5 & 3,9 & & 3,9 & & & \\
\hline 10 & 2 & 2 & 1 & 1 & 1 & 6 & 4 & 3,4 & 3,4 & & & & \\
\hline 11 & 3 & 4 & 6 & 5 & 2 & 5 & 6 & 5,3 & & & & 5,3 & \\
\hline 12 & 2 & 5 & 6 & - & 4 & 5 & 4 & 5,4 & 5,4 & & & & \\
\hline 13 & 2 & 3 & 6 & - & 3 & 6 & 5 & 5,4 & & & & & 5,4 \\
\hline 14 & 4 & 5 & 5 & 4 & 2 & 6 & 5 & 5,6 & & & 5,6 & & \\
\hline 15 & 5 & 5 & 6 & - & 2 & 6 & 5 & 6,3 & & 6,3 & & & \\
\hline & & & & & & & \multicolumn{2}{|c|}{ MÉDIAS FINAIS } & 4,4 & 4,7 & 5,5 & 4,4 & 4,3 \\
\hline
\end{tabular}

Fonte: Elaborada pelos autores

O gráfico da Figura 4 ilustra o desempenho resultante das pontuações obtidas pelo CASNAV para a inovação de ruptura. 
Figura 4 - Desempenho do CASNAV na Inovação de Ruptura

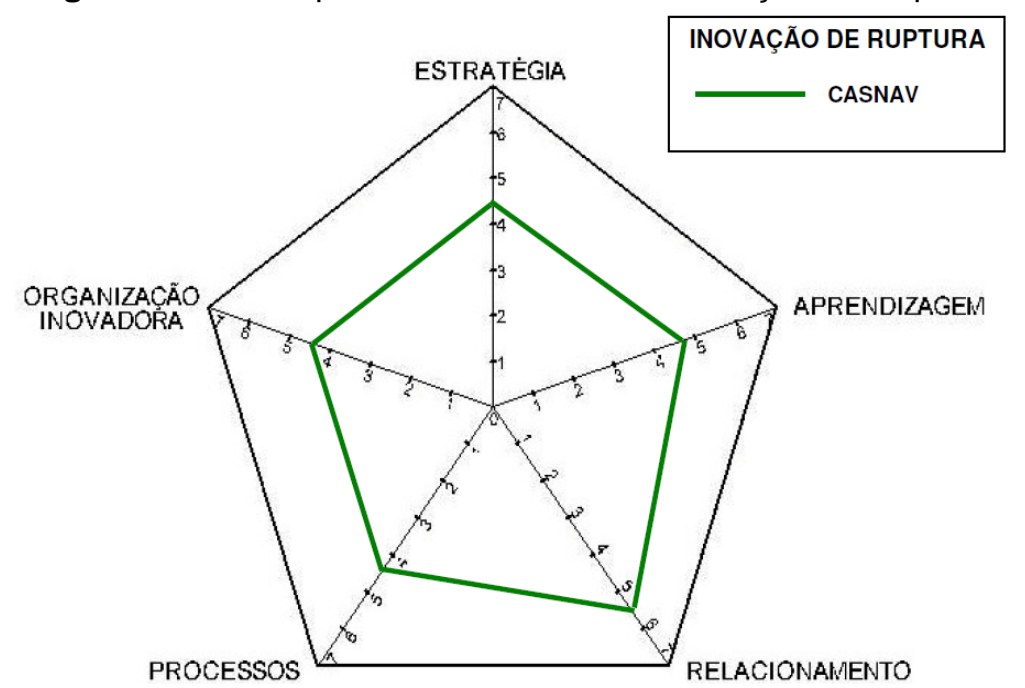

Fonte: Elaborada pelos autores

Como se pode observar na Tabela 3 e na Figura 4, as pontuações médias do CASNAV relativas à inovação de ruptura situaram-se em patamares inferiores ao da condição estável, entre os valores de 4,3 e 5,5, novamente com melhor avaliação em Relacionamentos Eficazes (5,5), e com resultados inferiores em Organização Inovadora (4,3), Estratégia e Processos Organizacionais (ambos com 4,4) e Aprendizagem $(4,7)$, com diferenças pouco significativas entre estes componentes. Avaliando-se as pontuações obtidas pelo CASNAV, verifica-se oportunidades de mudanças nestes quatro últimos componentes citados, com vistas a criar melhores condições para o gerenciamento de inovações de ruptura que, como já abordado anteriormente, pode ter importância estratégica no contexto do setor da defesa.

As condições de avanço são perceptíveis ou ao menos estão presentes, conforme exposto por um dos pesquisadores, segundo o qual "nossa gestão permite certa agilidade nas respostas das oportunidades que nos levem a inovações de ruptura". Parece haver no entanto uma concepção linear ou etapista, conforme transparece na fala de outro pesquisador, para quem "a inovação de ruptura só será o foco da nossa organização após estar completamente disseminado o conceito básico de inovação tecnológica e de proteção à propriedade intelectual nos produtos e serviços prestados pelo CASNAV".

Assim, observa-se que há uma menor ênfase na gestão da inovação de ruptura, ou ao menos uma concepção linear que a pressupõe como desdobramento da inovação em condição estável. Esse é um obstáculo a ser superado quando se quer conduzir a organização para um modo "ambidestro", dando conta simultaneamente da condição estável e da ruptura. De qualquer forma, é salutar a constatação desse fato pela própria organização, o que deve contribuir para a busca das melhorias devidas.

Com relação à auto-avaliação do IPqM em termos de inovação de ruptura, foram respondidos 17 questionários, cujas pontuações estão apresentadas na Tabe- 
la 4 , a seguir.

Tabela 4 - Respostas aos questionários IPqM - Inovação de Ruptura

\begin{tabular}{|c|c|c|c|c|c|c|c|c|c|c|c|c|c|c|c|c|c|c|c|c|c|c|}
\hline \multicolumn{18}{|c|}{ IPqM - INSTITUTO DE PESQUISAS DA MARINHA } & \multirow{3}{*}{ 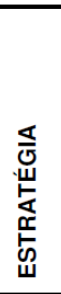 } & \multirow{3}{*}{ 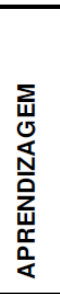 } & \multirow{3}{*}{ 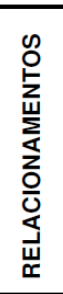 } & \multirow{3}{*}{ 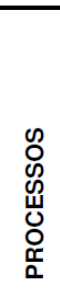 } & \multirow{3}{*}{ 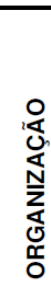 } \\
\hline \multicolumn{3}{|c|}{\begin{tabular}{|l} 
QUESTIONÁRIO \\
ORGANIZAÇÃOO
\end{tabular}} & \multicolumn{2}{|c|}{ QUÃO } & BEM & A É & \multicolumn{3}{|c|}{ GERENCIADA } & \multicolumn{2}{|c|}{ A A } & \multicolumn{2}{|c|}{ INOVAÇÃO } & DE $F$ & \multicolumn{3}{|c|}{ RUPTURA NESTA } & & & & & \\
\hline QUESTÃO & 1 & 2 & 3 & 4 & $\frac{Q 1}{5}$ & UEST & TION & $\begin{array}{l}\text { VÁR| } \\
8\end{array}$ & OS & $\frac{\text { RESP }}{10}$ & OND & $\mid$ & $\begin{array}{l}\text { S } \\
13\end{array}$ & \begin{tabular}{l|l|}
14 & 15 \\
\end{tabular} & \begin{tabular}{|l|l|}
5 & 16 \\
\end{tabular} & 17 & MÉDIAS & & & & & \\
\hline 1 & 2 & 5 & 3 & 1 & 1 & 4 & - & 3 & 5 & 6 & \begin{tabular}{|l|}
4 \\
\end{tabular} & 6 & 3 & \begin{tabular}{l|l}
2 & 1
\end{tabular} & 3 & \begin{tabular}{|l|}
2 \\
\end{tabular} & 3,2 & 3,2 & & & & \\
\hline 2 & 2 & 2 & 3 & 1 & 1 & 3 & - & 1 & 5 & 5 & 1 & 4 & 2 & \begin{tabular}{l|l}
2 & 1 \\
\end{tabular} & 3 & 2 & 2,4 & & & & 2,4 & \\
\hline 3 & 1 & 4 & 4 & 3 & 3 & 4 & - & 3 & 4 & 3 & 3 & 3 & 4 & \begin{tabular}{l|l|}
4 & 1 \\
\end{tabular} & 2 & 2 & 3,0 & & & & & 3,0 \\
\hline 4 & 3 & 3 & 2 & 2 & 2 & 4 & - & 1 & 6 & 6 & 1 & 4 & 1 & \begin{tabular}{l|l|}
3 & 1 \\
\end{tabular} & 3 & 2 & 2,8 & & 2,8 & & & \\
\hline 5 & 1 & 5 & 2 & 3 & 3 & 4 & - & 1 & 4 & 6 & 4 & 4 & 4 & 3 & 3 & 3 & 3,3 & & & 3,3 & & \\
\hline 6 & 2 & 3 & 2 & 3 & 3 & 3 & - & 1 & 5 & 5 & 2 & 4 & 3 & \begin{tabular}{l|l}
1 & 1 \\
\end{tabular} & 2 & 2 & 2,6 & & & & 2,6 & \\
\hline 7 & 5 & 6 & 3 & 2 & 2 & 4 & - & 4 & 4 & 5 & 4 & 5 & 3 & \begin{tabular}{l|l}
4 & 4 \\
\end{tabular} & 7 & 5 & 4,2 & & & 4,2 & & \\
\hline 8 & 1 & 5 & 1 & 1 & 1 & 4 & - & 11 & 1 & 3 & 1 & 1 & 2 & \begin{tabular}{l|l}
1 & 1 \\
\end{tabular} & 1 & 1 & 1,6 & & & & & 1,6 \\
\hline 9 & 1 & 5 & 2 & 2 & 2 & 4 & 3 & 2 & 4 & 3 & 1 & 4 & 2 & \begin{tabular}{l|l|}
2 & 1 \\
\end{tabular} & 2 & 1 & 2,4 & & 2,4 & & & \\
\hline 10 & 1 & \begin{tabular}{|l|}
1 \\
\end{tabular} & 1 & 1 & 1 & 4 & 3 & 11 & 1 & 3 & 1 & 3 & 2 & \begin{tabular}{l|l}
2 & 1 \\
\end{tabular} & 1 & 1 & 1,6 & 1,6 & & & & \\
\hline 11 & 3 & 1 & 2 & 2 & 2 & 3 & 3 & 1 & 3 & 3 & 1 & 3 & 2 & \begin{tabular}{l|l}
2 & 1 \\
\end{tabular} & 2 & 1 & 2,1 & & & & 2,1 & \\
\hline 12 & 4 & 2 & 4 & 3 & 2 & 4 & 3 & 4 & 5 & 4 & 5 & 3 & \begin{tabular}{|l|}
4 \\
\end{tabular} & \begin{tabular}{l|l|}
4 & 1 \\
\end{tabular} & 2 & 2 & 3,3 & 3,3 & & & & \\
\hline 13 & 3 & \begin{tabular}{|l|}
7 \\
\end{tabular} & \begin{tabular}{|l|}
2 \\
\end{tabular} & 2 & 2 & 4 & 4 & 3 & 4 & 5 & 4 & 4 & 4 & \begin{tabular}{l|l|l}
4 & 4 \\
\end{tabular} & \begin{tabular}{|l|l|}
12 \\
\end{tabular} & 2 & 3,5 & & & & & 3,5 \\
\hline 14 & 4 & \begin{tabular}{|l|}
5 \\
\end{tabular} & 2 & 6 & 6 & 5 & 4 & 3 & 6 & 6 & 4 & 6 & \begin{tabular}{|l|}
4 \\
\end{tabular} & \begin{tabular}{l|l}
2 & 5 \\
\end{tabular} & \begin{tabular}{|l|l|}
5 \\
\end{tabular} & 2 & 4,3 & & & 4,3 & & \\
\hline 15 & 2 & 3 & \begin{tabular}{|l|}
1 \\
\end{tabular} & 7 & 7 & 4 & 3 & 1 & \begin{tabular}{|l|}
1 \\
\end{tabular} & 5 & 2 & 4 & 2 & \begin{tabular}{l|l|}
3 & 1 \\
\end{tabular} & 2 & 3 & 3,0 & & 3,0 & & & \\
\hline & & & & & & & & & & & & & & & & & $\begin{array}{l}\text { UEDIAS } \\
\text { FINAIS }\end{array}$ & 2,7 & 2,7 & 3,9 & 2,4 & 2,7 \\
\hline
\end{tabular}

Fonte: Elaborada pelos autores

Na Figura 5, abaixo, é ilustrado o desempenho resultante das pontuações obtidas pelo IPqM para a inovação de ruptura.

Figura 5 - Desempenho do IPqM na Inovação de Ruptura

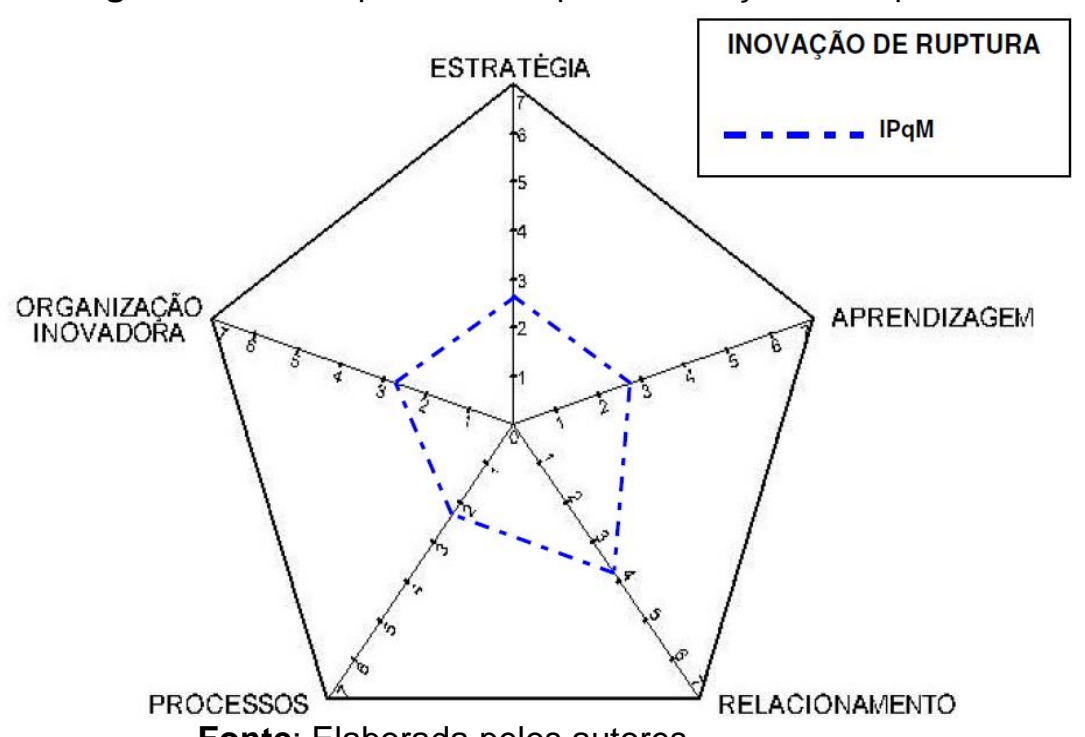

Fonte: Elaborada pelos autores

Conforme pode ser constatado analisando-se a Tabela 4 e a Figura 5, em termos de inovação de ruptura, as avaliações do IPqM também situaram-se em patamares inferiores ao da condição estável, com o máximo de 3,9 (em Relacionamentos Eficazes) e 2,4 (em Processos Organizacionais). As três demais 
componentes (Aprendizagem, Estratégia e Organização Inovadora) apresentaram idêntica pontuação $(2,7)$.

Pelo fato do IPqM atuar em uma área mais hard do que o CASNAV, como materiais e sistemas inerciais, sistemas sonar, armas, guerra eletrônica, sua concepção de inovação parece se aproximar mais da perspectiva de inovação tecnológica de produto e processo (TPP), presente nas duas primeiras versões do Manual de Oslo. Isso fica claro na exposição de um pesquisador, ao afirmar que "para o desenvolvimento de uma inovação é necessário o investimento no aprimoramento da equipe, a compra de equipamentos e a realização de experimentos".

Portanto, há uma percepção mais clara do papel do tempo e dos investimentos sustentáveis em capital, necessários aos processos de inovação, bem como da dificuldade em provê-los e garanti-los usando-se apenas os instrumentos financeiros clássicos, conforme visto em Christensen, Kaufman e Shih (2008). Tal perspectiva estratégica transparece na fala do pesquisador que constata a importância de se manter o investimento de capital "durante um período de tempo em que não se obtém os resultados desejados".

Como ocorrera no caso da inovação em condição estável, também aqui, os pesquisadores do IPqM mostraram alta dispersão das suas percepções com relação ao diagnóstico de inovação na instituição, com as implicações já destacadas de fragilização do uso da média como indicador. De qualquer forma, também aqui, é válido enxergar de um lado, possíveis problemas de intercomunicação entre os pares, com reflexos organizacionais, mas também, em uma perspectiva otimista, enxergar elementos que constituem a condição capacitadora da autonomia, como exposto por Takeuchi e Nonaka (2008).

\section{CONSIDERAÇÕES FINAIS}

O trabalho permitiu identificar que os órgãos da Marinha estudados reúnem, em diferentes níveis de profundidade e com diferentes perspectivas acerca do papel e da dinâmica da inovação, componentes que caracterizam a organização inovadora: comprometimento da alta gestão, desenvolvimento individual contínuo, foco externo, ambiente criativo e aprendizagem.

Apesar disso, como era esperado, há um desequilíbrio entre a perspectiva da inovação em condição estável e a inovação de ruptura, deixando antever que a organização ainda não se situa nos marcos da chamada "organização ambidestra". No entanto, ressalta-se que dos componentes que mais se destacam no radar da inovação de ruptura, para ambas as organizações estudadas, está a dimensão "Relacionamentos", responsável em grande parte pela produção e sustentação de uma cultura inovadora e portanto pela criação de capacidades dinâmicas que podem implicar na direção da ambidestralidade. 
Do ponto de vista da formalização de ações de gestão da inovação, o CASNAV possui um modelo de gestão estratégico implantado desde 2001, com princípios de inovação presentes, permitindo sua continuidade e aprimoramento. Este modelo, muito provavelmente, está na raiz da manutenção de relacionamentos permeáveis à inovação e portanto pode ser tomado como ponto de partida para um programa de avanço na direção da inovação de ruptura. Já com relação ao IPqM, embora a percepção do papel estratégico da inovação esteja forte e criticamente presente, o estudo não conseguiu, dada a forte dispersão das percepções capturadas, atribuída pelos autores à autonomia, independência e baixa comunicação intergrupos, identificar um padrão de ações que recepcionem a gestão da inovação de forma sistemática e proativa. No entanto, a natureza tecnológica e o espírito crítico na instituição, revelados nas questões abertas dos questionários, permitem antever uma possibilidade de ambidestralidade alimentada pela visão estratégica, e portanto, de longo prazo, dos processos e projetos de inovação.

Sugere-se para futuros estudos, além do aprofundamento da pesquisa no CASNAV e no IPqM, que teve apenas um caráter exploratório, ampliando e desdobrando os achados encontrados na presente pesquisa, particularmente enfrentando a questão da dispersão elevada dos resultados no IPqM, a replicação da auditoria da gestão da inovação para as outras duas organizações de C\&T: o Centro Tecnológico da Marinha em São Paulo (CTMSP) e o Instituto de Estudos do Mar Almirante Paulo Moreira (IEAPM).

\section{REFERÊNCIAS}

ABERNATHY, W. J., UTTERBACK, J. M. Patterns of industrial innovation. Technology Review, v. 80, n. 7, p. 40-47, 1978.

AGOSTINI, Lara, NOSELLA, Anna, FILIPINI, Roberto. Towards an integrated view of the ambidextrous organization: a second-order fator model. Criativity and Innovation Management. v. 25, n. 1, 2016. DOI 10.1111/caim.12167.

BACK, Luani; KOVALESKI, João Luiz; ANDRADE JUNIOR, Pedro Paulo. Transferência e auditoria tecnológica no processo de determinação de estratégias tecnológicas: estudo de caso. Revista Produção Online, Florianópolis, SC, v. 14, n. 1, p. 171-194, jan./mar. 2014. http://dx.doi.org/10.14488/1676-1901.v14.i1.1573.

BESSANT, John; TIDD, Joe. Inovação e Empreendedorismo. Porto Alegre: Bookman, 2009.

BIN, Adriana. Planejamento e Gestão da Pesquisa e da Inovação: conceitos e instrumentos. Tese (Doutorado em Política Científica e Tecnológica). Campinas: UNICAMP, 2008.

BREM, Alexander, NYLUND, Petra A., SCHUSTER, Gerd. Innovation and de facto standardization: The influence of dominant design on innovative performance, radical innovation, and process innovation. Technovation, 50-51, p. 79-88, 2016.

http://dx.oi.org/10.1016/j.technovation.2016.01.006. 
CHRISTENSEN, Clayton M., KAUFMAN, Stephen P., SHIH, Willy. Innovation Killers: How Financial Tools Destroy Your Capacity to Do New Things. Harvard Business Review, January 01, 2008. DOI: 10.9790/487X-17210712.

CONSTANTE, Jonas Mendes; FIALA, Nathalia; ANDREASSI, Tales. Geração de spin-offs tecnológicos - um estudo multicaso. Revista Produção Online, Florianópolis, SC, v. 14, n. 2, p. 617-647, abr./jun. 2014. http://dx.doi.org/10.14488/1676-1901.v14i2.1436.

DE NEGRI, José Fernando. A nova estrutura de Ciência, Tecnologia e Inovação da Marinha. Revista Pesquisa Naval, Brasília, nov. 2008. n. 21, p. 9-16.

DOLOREUX, David; MELANÇON, Yannik. On the dynamics of innovation in Quebec's coastal maritime industry. Technovation, v.28, n.4, p. 231-243, abr. 2008. DOI: 10.1016/j.technovation.2007.10.006.

DRUCKER, Peter F. The Discipline of Innovation. Harvard Business Review, p. 149-157, nov. 1998.

FIGUEIREDO, Paulo Negreiros. Gestão da Inovação: Conceitos Métricas e Experiências no Brasil. Editora LCT, 2009.

FIGUEIREDO, Paulo Negreiros, FONSECA, Marcelio. Acumulação de capacidades tecnológicas e aprimoramento de performance operacional: evidências de um estudo de caso em nível de empresa. Revista Brasileira de Inovação, v. 13, n. 2, p. 311-344, julho/dezembro 2014.

GADELHA, Carlos Augusto Graboi, VARGAS, Marco Antonio, MALDONADO, José Manuel dos Santos, BARBOSA, Pedro Ribeiro. O complexo econômico-industrial da saúde no Brasil: dinâmica de inovação e implicações para o Sistema Nacional de Inovação em saúde. Revista Brasileira de Inovação, v. 12, n. 2, p. 251-282, julho/dezembro 2013.

GONZAGA, David Brandão, MUNIZ JÚNIOR, Jorge. Obtenção do nível de atendimento de competências de alto valor. Revista Produção Online, Florianópolis, SC, v. 16, n. 1, p. 151181, jan./mar. 2016. DOI: http://dx.doi.org/10.14488/1676-1901.v16i1.2040.

GOVINDARAJAN, Vijay, TRIMBLE, Chris. O outro lado da inovação: a execução como fator crítico de sucesso. Rio de Janeiro: Elsevier, 2010.

GRIZENDI, Eduardo. Manual de Orientações Gerais sobre Inovação. Ministério das Relações Exteriores. Brasília, 2011.Disponível em:

<www.finep.gov.br/dcom/manualinovacao.pdf>. Acesso em: 14 jun. 2011.

GUIMARÃES, Tomás de Aquino; CAVALCANTI Gustavo Henrique de V.; AFFONSECA Maria Dulce Valença de. Gestão da qualidade e inovações gerenciais em organizações públicas. In: Encontro da Associação Nacional de Pós-Graduação e Pesquisa em Administração, 2004, Curitiba. Anais eletrônicos ...Rio de Janeiro: ANPAD, 2004.

LAZZARI, Fernanda; BAMPI, Rodrigo Eduardo; MILAN, Gabriel Sperandio. Os esforços de inovação e sua relação com alguns indicadores de desempenho do negócio. Revista

Produção Online, Florianópolis, SC, v. 14, n. 1, p. 58-83, jan./mar. 2014.

http://dx.doi.org/10.14488/1676-1901.v14.i1.1428. 
NOSELLA, A., CANTARELLO, S., FILIPPINI, R. The intelectual structure of organizational ambidexterity: A bibliometric investigation into the state of the art. Strategic Organization, $v$. 10, 450-465, 2012. DOI: 10.1177/1476127012457979.

OCDE - Organização para a Cooperação e o Desenvolvimento Econômico. Manual de Oslo - proposta de diretrizes para coleta e interpretação de dados sobre inovação tecnológica. Tradução feita pela FINEP. 2 ed. 2004.

Disponível em: <http://www.mct.gov.br/upd_blob/0005/5069.pdf>. Acesso em: 21 jun. 2011.

OCDE - Organização para a Cooperação e o Desenvolvimento Econômico. Manual de Oslo - proposta de diretrizes para coleta e interpretação de dados sobre inovação tecnológica. Tradução feita pela FINEP. 3 ed. 2007. Disponível em: <http://www.mct.gov.br/upd_blob/0005/5069.pdf>. Acesso em: 21 jun. 2011.

ROBERTSON, PI ; CASALI, GI ; JACOBSON, D. Managing open incremental process innovation: Absorptive Capacity and distributed learning. Research Policy, v.41, n.5, p.822832. jun. 2012. DOI: 10.1016/j.respol.2012.02.008.

SCHOTT, Thomas, JENSEN, Kent Wickstrom. Firms' innovation benefiting from networking and institutional support: A global analysis of national and firm effects. Research Policy, v. 45, n. 6, p. 1233-1246, July 2016. http://dx.doi.org/10.1016/j.respol.2016.03.006 .

SCHUMPETER, Joseph A. Capitalismo, socialismo e democracia. Rio de Janeiro: Zahar Editora, 1942.

SILVA, Evaldo Henrique, HASENCLEVER, Lia. Regime tecnológico e emergencia dos padrões de estratégias inovativas das firmas. Revista Brasileira de Inovação, CampinasSP, v. 13, n. 1, p. 45-76, janeiro/junho 2014.

SUNDARRAJ, Vijay Kumar Rangaraja P. Schumpeterian innovation patterns and firmperformance of global technology companies. European Journal of Innovation Management, v.19, n. 2, 2016. http://dx.doi.org/10.1108/EJIM-05-2015-0034.

TAKEUCHI, Hirotaka; NONAKA, Ikujiro. Gestão do conhecimento. Porto Alegre: Bookman, 2008. 320 p.

TIDD, Joe; BESSANT, John; PAVITT, Keith. Gestão da inovação. 3 ed. Porto Alegre: Bookman, 2008. 600 p.

TIGRE, Paulo Bastos. Gestão da inovação: a economia da tecnologia no Brasil. Rio de Janeiro: Campus/Elsevier, 2006.

TUSHMAN, M. L., O'REILLY, C.A. Ambidextrous Organizations: Managing Evolutionary and Revolutionary Change. California Management Review, 38, 1-23.

YIN, Robert K. Estudo de caso: planejamento e métodos. 2. ed. Porto Alegre: Bookman, 2001.

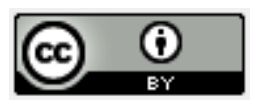

Artigo recebido em 15/02/2016 e aceito para publicação em 10/03/2016

DOI:http://dx.doi.org/ 10.14488/1676-1901.v16i4.2353 